\title{
Logistics and maritime systems
}

\author{
Ek Peng Chew • Marielle Christiansen • \\ Hans-Otto Günther • Kap Hwan Kim • \\ Herbert Kopfer
}

Published online: 13 March 2015

(c) Springer Science+Business Media New York 2015

In today's global economy, businesses in all parts of the world are interlinked by logistics chains. Particularly, maritime systems play a vital role in the intercontinental transportation of goods. In order to meet the rising global handling volumes and the customers' demand for quick and on-time delivery, shipping liners as well as terminal operators and software companies have developed new management and technological solutions, e.g. on pricing for logistics services, the handling of containers under conditions of scarce resources, the application of advanced information technology, and the establishment of intermodal links to coastal and on-land transportation systems. A further challenge is the consideration of environmental effects which are

\section{E. P. Chew}

Department of Industrial and Systems Engineering, National University of Singapore, 1 Engineering Drive 2, Singapore, Singapore

e-mail: isecep@nus.edu.sg

\section{Christiansen}

Department of Industrial Economics and Technology Management, Norwegian University of Science and Technology, 7491 Trondheim, Norway

e-mail: marielle.christiansen@iot.ntnu.no

\section{H.-O. Günther $(\square)$}

Department of Industrial Engineering, Seoul National University, Seoul 151-744, Korea e-mail: guenther@snu.ac.kr

\section{K. H. Kim}

Department of Industrial Engineering, Pusan National University, 30 Changjeon-Dong,

Kumjeong-Ku, Busan 609-735, Korea

e-mail: kapkim@pusan.ac.kr

\section{H. Kopfer}

Department of Logistics, University of Bremen, Wilhelm-Herbst-Straße 5, 28359 Bremen, Germany e-mail: kopfer@uni-bremen.de 
gaining increasing importance in politics and society. As a result, global freight networks are emerging which combine maritime transport, inland waterways and onshore road and rail transportation systems.

The primary objective of this special issue is to reflect the recent developments in maritime and landside transport and to examine research issues concerned with quantitative analysis and decision support for freight transport and maritime logistics systems. For this special issue thirteen papers have been selected for publication after a thorough peer-review according to the standards of the FSM journal. In addition one erratum is included.

\section{Papers in the special issue}

The first paper by $N$. K. Tran and H.-D. Haasis provides a comprehensive literature review on optimization problems, methodologies as well as research tendencies in the area of network optimization in container liner shipping. Specifically, container routing, fleet management and network design are addressed. As challenging developments in the container liner shipping industry the authors identify the increased market power of a small number of giant operators, the deployment of mega vessels as an important strategy to reap low shipping cost, the emergence of strategic alliances that link operators together, and the expansion of shipping lines into hinterland operation.

The subsequent paper by I. Norstad, K. Fagerholt, L. M. Hvattum, H. S. Arnulf, and $A$. Bjфrkli studies a real ship routing and scheduling problem faced by a Norwegian shipping company which is specializing in the world wide transportation of forest products and break bulk cargoes. This problem is considered as a fleet deployment problem with voyage separation requirements. Two mathematical formulations are presented, an arc flow and a path flow model. Computational results show that the path flow model can be solved for problems of realistic size and yields solutions with a much better spread of voyages.

The third paper by $S$. Zurheide and K. Fischer deals with the application of revenue management methods for liner shipping companies. Based on a slot allocation model for container bookings, three different booking acceptance strategies are studied and compared with respect to their applicability in liner shipping and their performance regarding profit and capacity utilization. In a simulation study, these strategies are evaluated for different scenarios. The simulation study shows that a new bid-price strategy developed by the authors generates very promising results compared to previously published booking limit strategies.

Another review paper by H. J. Carlo, I. F. A. Vis, and K. J. Roodbergen considers seaside operations as the bottleneck in a container terminal. The paper presents an in-depth overview of these operations and highlights current trends and developments. Moreover, the paper identifies new avenues for academic research based on current trends and developments in the container terminal industry like advanced control strategies for bottleneck resources, non-traditional berth and terminal layouts, and increased automation of transport and yard-side operations. 
In their paper, D. Ambrosino, M. Paolucci, and A. Sciomachen investigate the socalled master bay planning problem, i.e. stowing a given set of different type containers in the available slots of a containership considering the whole route of the ship and the loading/unloading of containers at the successive ports of the ship's route. The paper introduces two mixed integer programming models aimed to deal with practical and operative aspects of the problem. The results of an extensive computational experimentation show the effectiveness of the proposed models and the related solution methods.

The paper by M.-K. Lee addresses the allocation of limited yard storage space to export containers in a terminal under heavy workload situations. A hierarchical analytical method is introduced that decomposes the planning procedure into two stages. First, the workload distribution across the whole yard is balanced. Thereafter, a flexible yard allocation strategy is applied in order to assign storage locations to export containers so as to facilitate yard crane operation and to increase yard space utilization. Experimental results show the efficiency of this solution methodology.

The allocation of straddle carriers at intermodal container terminals is the topic of the paper by E. Zehendner, G. Rodriguez-Verjan, N. Absi, S. Dauzère-Pérès, and D. Feiller. At the tactical level, a deterministic optimization model is developed based on a network flow representation of the terminal. Because truck arrivals, handling and travel times of straddle carriers are subject to uncertainty, a simulation model is applied to validate the quality of the optimization model. Numerical results show that the allocation proposed by the optimization model reduces delays at the terminal and performs well in a stochastic environment.

In their paper, R. Choe, T. S. Kim, T. Kim, and K. R. Ryu develop a method for scheduling stacking cranes at yard blocks of an automated container terminal so as to process not only the requested jobs at hand but also the re-marshalling jobs whenever possible to speed up future loading operations and thereby to improve the utilization of the cranes and reduce waiting times of transport vehicles. The authors combine algorithms for selecting and scheduling the crane jobs. Simulation experiments show the superior performance of the proposed strategy compared to a conventional strategy which does not prospectively schedule the re-marshalling jobs.

The real-time container assignment of storage locations at a transshipment terminal is the topic of the paper by M. E. H. Petering. Several real-time container storage strategies are proposed and evaluated by a fully-integrated, discrete event simulation model of a vessel-to-vessel transshipment terminal. Through comprehensive simulation studies, it is shown that the overall productivity at a terminal can be considerably improved by use of the proposed real-time stacking strategies compared to random stacking. Simulation results further indicate that productivity gains depend on the stochasticity of a real-world terminal.

The subsequent contribution by S. Sterzik, H. Kopfer, and W. Y. Yun addresses the movement of full and empty containers between a seaport and its hinterland and gaining possible benefits of exchanging empty containers between cooperating trucking companies. Mixed integer programming models that consider vehicle routing and scheduling simultaneously are presented and solved by means of an 
efficient tabu search heuristic. Numerical results show that container sharing between trucking companies leads to remarkable cost savings, especially, if tight time windows are considered.

A similar problem of transporting $40 \mathrm{ft}$ or alternatively one or two $20 \mathrm{ft}$ containers by truck in a local area before or after a long-distance transportation by vessel or by train is considered in the paper by R. Zhang, W. Y. Yun, and H. Kopfer. Based on a state-transition representation, they model this problem as a sequencedependent multiple-travelling salesman problem and develop three tree search procedures and an improved reactive tabu search algorithm. Numerical experiments using a real-world data set show the efficiency and effectiveness of the tree search solution principle.

Hinterland transportation of containers is also addressed in the paper by Z. Xue, W.-H. Lin, L. Miao, and C. Zhang. They examine this problem under a special operation mode in which tractors and trailers can be separated, i.e. tractors can be assigned to a new task at another location while trailers are waiting for packing or unpacking. The problem is formulated as a vehicle routing and scheduling problem with temporal constraints. For solving large-scale problems, a max-min ant colony optimization algorithm is developed. Numerical experiments with randomly generated instances demonstrate the performance of the algorithm.

The final paper by X. Feng, I. Moon, and J. Shin presents new hybrid genetic algorithms for solving the three-dimensional multiple container packing problem, i.e. determining non-overlapping packing patterns of a set of finite threedimensional rectangular items into the minimum number of identical containers. Experiments were conducted to demonstrate the performance of the algorithms compared with the existing algorithms. The numerical results show that the proposed hybrid genetic algorithms yield superior solutions in a reasonable amount of time.

\section{Concluding remarks}

This special issue has greatly benefited from the cooperation among the authors, reviewers, and editors. We would like to express our sincere thanks to the reviewers for their excellent and timely refereeing. Last, but not least, we thank all authors for their contributions which made this special issue possible. 